\title{
The prognostic significance of protein arginine methyltransferase 6 expression in colon cancer
}

\author{
Yongchul Lim ${ }^{1, *}$, Suyeun $\mathrm{Yu}^{2, *}$, Jung-A Yun ${ }^{3}$, In-Gu Do ${ }^{4}$, Lan Cho ${ }^{5}$, Yang Hee Kim ${ }^{5}$ \\ and Hee Cheol Kim ${ }^{1}$ \\ ${ }^{1}$ Department of Surgery, Samsung Medical Center, Sungkyunkwan University School of Medicine, Seoul, Korea \\ ${ }^{2}$ Department of Preventive Medicine, College of Medicine, Korea University, Seoul, Korea \\ ${ }^{3}$ Department of Surgery, Hanyang University Guri Hospital, Hanyang University College of Medicine, Guri, Korea \\ ${ }^{4}$ Department of Pathology, Kangbuk Samsung Hospital, Sungkyunkwan University School of Medicine, Seoul, Korea \\ ${ }^{5}$ Department of Surgery, Samsung Medical Center, Biomedical Institute, Seoul, Korea \\ *These authors contributed equally to this work as first authors \\ Correspondence to: Hee Cheol Kim, email: hckim@skku.edu
}

Keywords: colon cancer; protein arginine methylation; PRMT6; apoptosis; prognosis

Received: December 07, $2016 \quad$ Accepted: November 16, $2017 \quad$ Published: December 27, 2017

Copyright: Lim et al. This is an open-access article distributed under the terms of the Creative Commons Attribution License 3.0 (CC BY 3.0), which permits unrestricted use, distribution, and reproduction in any medium, provided the original author and source are credited.

\section{ABSTRACT}

Protein arginine methylation is involved in cellular differentiation and proliferation. Recently, aberrant expression of protein arginine methyltransferases, which are responsible for the methylation reaction, has been reported in various types of cancer. However, there is no clear evidence regarding the prognostic value of abnormal PRMT6 expression in colorectal cancer or the effect of PRMT6 regulation on CRC cells. We investigated the expression patterns of PRMT6 in patients with stage II and III CRC. We detected nuclear expression of PRMT6 in $23.7 \%$ of carcinoma samples by immunohistochemistry. Among the clinicopathological parameters, the ratio of poorly differentiated cancer cells was approximately two-fold higher in patients with PRMT6-positive disease than in those with PRMT6-negative disease $(p=0.002)$. Patients with PRMT6-positive CRC had a shorter disease-free survival than those with PRMT6-negative CRC in both univariate and multivariate analyses ( $p=0.018$ and $p$ $=0.035$, respectively). siRNA-mediated inhibition of PRMT6 expression in CRC cells induced $\mathrm{p} 21^{\mathrm{WAF} 1 / \mathrm{CIP} 1}$ overexpression and suppressed cell growth and colony-forming ability. Concomitantly, apoptosis was induced in PRMT6-suppressed CRC cells. These data suggest that PRMT6 can serve as a biomarker for unfavorable prognosis and as a therapeutic target in CRC.

\section{INTRODUCTION}

Colorectal cancer (CRC) is one of the most commonly diagnosed cancers and fourth most common cause of cancer-related death worldwide [1]. CRC typically develops slowly, over a period of 10-20 years [2], and the accumulation of genetic and epigenetic alterations is involved in the initiation and progression of the disease. The most notable genetic changes in colorectal carcinogenesis include alterations in APC, KRAS, SMAD4, TP53, and the mismatch repair genes $M L H 1$ and $M S H 2$ $[3,4]$. Hypermethylation of $\mathrm{CpG}$ islands in a certain panel of genes also contributes to disease development, and this phenotype is often associated with $B R A F$ mutations [5]. Nevertheless, the molecular pathogenesis of CRC is heterogeneous and remains poorly understood.

Arginine methylation is a common posttranslational modification catalyzed by protein arginine methyltransferases (PRMTs) that use $S$-adenosylmethionine as the methyl donor [6]. PRMTs are classified into two groups according to their products. Type I enzymes (PRMT1, 2, 3, 4, 6, and 8) can generate asymmetric $N G$, NG-dimethyl-arginine, while type II (PRMT5 and PRMT7) produce symmetric $N G, N^{\prime} \mathrm{G}$-dimethyl-arginine. Arginine methylation has been implicated in signal transduction, transcription, 
mRNA splicing, and DNA damage response, and affects protein-protein interactions and protein localization [7]. Correspondingly, arginine methylation has been linked to carcinogenesis, metastasis, and drug resistance [8, 9], and dysregulation of PRMTs is often associated with diverse types of cancer [10]. Recently, some PRMTs have emerged as promising targets for cancer therapeutic strategies [11].

Among the PRMTs, PRMT6 is localized exclusively in the nucleus [12] and the enzyme has been implicated in the regulation of nuclear processes, such as DNA repair and gene expression [13, 14]. Previously, we reported that PRMT6 expression is gradually reduced during the replicative senescence of WI-38 fibroblasts [15] and increased when the cell cycle proceeds from G0/G1 to $\mathrm{S}$ phase in HeLa cells [16]. It has been also reported that mouse embryonic fibroblasts from PRMT6 $^{-/}$embryos undergo rapid cellular senescence [17] and depletion of PRMT6 in MCF7 breast cancer cells induces senescence as well as cell cycle arrest [18]. The mechanism responsible for these phenomena is that PRMT6 acts as a transcriptional co-repressor by directly binding to the promoters of tumor suppressor genes such as p21 (CDKN1A or p21 waf1/CIP1) and p53 (TP53), where it methylates histone $\mathrm{H} 3$ arginine 2 [17-19]. In addition, methylation of p21 at arginine 156 by PRMT6 promotes the phosphorylation of threonine 145 on the protein and increased cytoplasmic localization of p21, resulting in HCT116 cell resistance to doxorubicin [20].

In clinical studies, PRMT6 was found to be upregulated in breast, cervix, bladder, prostate, and lung cancers $[21,22]$. However, the expression level of PRMT6 in CRC tissues and effect of the enzyme on CRC cell proliferation remain unclear. Therefore, we investigated whether PRMT6 positivity in clinical samples is significantly associated with clinicopathophysiologic features and patient survival. In addition, we examined whether PRMT6 depletion affects CRC cell proliferation and apoptosis.

\section{RESULTS}

\section{PRMT6 is overexpressed in CRC tissues}

We compared the expression level of PRMT6 in 24 matched samples from cancer tissues and adjacent normal tissues from the same patients by western blotting. As shown in Figure 1A and 1B, PRMT6 expression increased by more than 1.5 -fold in seven tumor samples matched with adjacent noncancerous tissues from the same patients. In addition, comparison of PRMT6 mRNA and protein levels between normal epithelial cells (NCM460D) derived from human colon mucosa and three CRC cell lines (DLD1, HCT116, and HT29) revealed that the three CRC lines highly expressed the PRMT6 gene compared to the NCM460D cells (Figure 1C). Among the CRC cell lines, both the mRNA and protein levels of PRMT6 were highest in HT29 cells (Figure 1C).

\section{PRMT6 expression is associated with clinicopathologic characteristics of CRC patients}

To determine the clinicopathological associations of PRMT6 in patients with CRC, we performed immunohistochemistry on $586 \mathrm{CRC}$ tissue samples. We found positive staining for PRMT6 in 23.7\% of CRC samples (139 of 586 patients) (Table 1 and Supplementary Table 2), and the enzyme was localized exclusively in the nucleus (Figure 2A and Supplementary Figure 1). Statistical analysis of PRMT6 positivity and standard clinicopathological variables showed that the ratio of poorly differentiated, mucinous, and signet ring cells in the cell type was approximately two-fold higher in the group with PRMT6 expression (15.8\%) than in the group without PRMT6 expression $(7.2 \%)(p=0.002)$, indicating that PRMT6 activity plays a critical role in cancer cell differentiation (Table 1). However, PRMT6 positivity did not show a significant association with other standard clinicopathological parameters (Table 1).

Next, to evaluate the correlation between PRMT6 expression and overall survival (OS) and disease-free survival (DFS), we first performed univariate analysis of traditional clinicopathological variables for prognosis. The presence of PRMT6 showed significance $(p=0.018)$ in the analysis of DFS with other clinicopathological factors (Supplementary Table 3). In multivariate analysis, PRMT6 positivity was also found to be an independent prognostic factor for shorter DFS ( $p=0.035$, Supplementary Table $3)$. Kaplan-Meier curves depicted significant differences in DFS between patients whose tumors had positive and negative expression of PRMT6 ( $p=0.035)$, but not in OS $(p=0.350)$ (Figure 2B). These results indicate that PRMT6 expression is a useful indicator of unfavorable prognosis in patients with CRC.

\section{Knockdown (KD) of PRMT6 inhibits growth and colony-formation in CRC cell lines}

To investigate the importance of PRMT6 in the proliferation of CRC cells, two different siRNA duplexes against human PRMT6 (siPRMT6 \#1, \#2) were used to knockdown the enzyme in three human CRC cell lines. Three days after siRNAs transfection, we examined cell proliferation activity. Two siRNAs for PRMT6 efficiently suppressed the expression of endogenous PRMT6 protein at $72 \mathrm{~h}$ post-transfection (Figure 3A) and PRMT6 KD significantly inhibited proliferation of CRC cells compared to in negative control siRNA (siNC)-transfected cells (Figure $3 \mathrm{~B}$ ). We also compared the colony-forming capability between siNC- and siPRMT6-transfected CRC cells. PRMT6-suppressed cells showed a marked reduction in colony formation rates compared with siNC-transfected cells (Figure 3C and 3D). These findings suggest a role for PRMT6 in promoting CRC cell proliferation and in the progression of CRC. 
Table 1: The association of the expression of PRMT6 (negative/positive) with the clinicopathologic variables

\begin{tabular}{|c|c|c|c|}
\hline & \multicolumn{2}{|c|}{ PRMT6 } & \multirow[b]{2}{*}{$p$-value } \\
\hline & $\begin{array}{l}\text { Negative } \\
(N=447)\end{array}$ & $\begin{array}{c}\text { Positive } \\
(N=139)\end{array}$ & \\
\hline $\begin{array}{l}\text { Gender } \\
\text { Female } \\
\text { Male }\end{array}$ & $\begin{array}{l}169(37.8) \\
278(62.2)\end{array}$ & $\begin{array}{l}52(37.4) \\
87(62.6)\end{array}$ & 0.933 \\
\hline $\begin{array}{l}\text { Location } \\
\text { Colon } \\
\text { Rectum }\end{array}$ & $\begin{array}{l}327(73.2) \\
120(26.8)\end{array}$ & $\begin{array}{c}109(78.4) \\
30(21.6)\end{array}$ & 0.214 \\
\hline $\begin{array}{l}\text { CEA level } \\
\leq 5 \mathrm{ng} / \mathrm{ml} \\
>5 \mathrm{ng} / \mathrm{ml}\end{array}$ & $\begin{array}{c}362(81.0) \\
85(19.0)\end{array}$ & $\begin{array}{c}116(83.5) \\
23(16.5)\end{array}$ & 0.512 \\
\hline $\begin{array}{r}\text { T stage } \\
\text { T1-2 } \\
\text { T3-4 }\end{array}$ & $\begin{array}{c}35(7.8) \\
412(92.2)\end{array}$ & $\begin{array}{c}5(3.6) \\
134(96.4)\end{array}$ & 0.084 \\
\hline $\begin{array}{c}\text { N stage } \\
\text { No } \\
\text { N+ }\end{array}$ & $\begin{array}{l}230(51.5) \\
217(48.5)\end{array}$ & $\begin{array}{l}78(56.1) \\
61(43.9)\end{array}$ & 0.336 \\
\hline $\begin{array}{l}\text { Cell type } \\
\text { WD/MD } \\
\text { PD/Muc/SRC }\end{array}$ & $\begin{array}{c}415(92.8) \\
32(7.2)\end{array}$ & $\begin{array}{l}117(84.2) \\
22(15.8)\end{array}$ & 0.002 \\
\hline $\begin{array}{l}\text { Lymphatic invasi } \\
\text { Negative } \\
\text { Positive }\end{array}$ & $\begin{array}{l}328(73.4) \\
119(26.6)\end{array}$ & $\begin{array}{c}102(73.4) \\
37(26.6)\end{array}$ & 0.999 \\
\hline $\begin{array}{l}\text { Vascular invasion } \\
\text { Negative } \\
\text { Positive }\end{array}$ & $\begin{array}{c}390(87.2) \\
57(12.8)\end{array}$ & $\begin{array}{l}114(82.0) \\
25(18.0)\end{array}$ & 0.120 \\
\hline $\begin{array}{l}\text { Perineural invasi } \\
\text { Negative } \\
\text { Positive }\end{array}$ & $\begin{array}{c}413(92.4) \\
34(7.6)\end{array}$ & $\begin{array}{c}130(93.5) \\
9(6.5)\end{array}$ & 0.655 \\
\hline $\begin{array}{l}\text { Adjuvant chemot } \\
\text { Yes } \\
\text { No } \\
\text { Undescribed }\end{array}$ & $\begin{array}{c}353(79.0) \\
34(7.6) \\
60(13.4)\end{array}$ & $\begin{array}{c}105(75.5) \\
11(7.9) \\
23(16.5)\end{array}$ & 0.637 \\
\hline
\end{tabular}

\section{Knockdown of PRMT6 upregulates tumor suppressor p21 protein in CRC cells}

In previous studies, PRMT6 was shown to function as a transcriptional repressor and control cell proliferation by H3R2 dimethylation and subsequent repression of tumor suppressors such as p21 and p53 [17-19]. Based on these reports, we examined the inter-relationships between PRMT6 and two tumor suppressor expressions as well as levels of H3R2 methylation in three CRC cells. CRC cell lines transfected with each of two siPRMT6s commonly showed significant increases in both $\mathrm{p} 21$ protein (Figure $4 \mathrm{~A}$ and $4 \mathrm{~B}$ ) and mRNA (Figure 4C). However, the changes in p53 expression and H3R2 dimethylation status were cell-type specific. DLD1 showed neither p53 induction nor H3R2 hypomethylation under PRMT6 knockdown, while PRMT6 downregulation in HT29 cells induced significant reductions in H3R2 methylation without altering p53 levels compared to siNC-transfected cells (Figure 4A). In HCT116 cells, PRMT6 knockdown induced p53 and p21 expression without H3R2 hypomethylation (Figure 4B left panel). To investigate the importance of p53 in siPRMT6mediated p21 induction in HCT116 cells, each siPRMT6 was transfected to a p53-null isogenic cell line. Although PRMT6 levels were significantly reduced in siPRMT6transfected isogenic cells, p21 expression was not induced (Figure 4B right panel), indicating that $\mathrm{p} 21$ induction by PRMT6 depletion depends on p53 upregulation in HCT116 cells. These results indicate that regulation of $\mathrm{p} 21$ expression involving PRMT6 is complex and depends on the cellular context and circumstances.

Next, we investigated the correlation between PRMT6 and p21 proteins as well as p53 in 24 tumor tissue samples as shown in Figure 1A by western blotting. When densitometric values corresponding to the two tumor suppressors and PRMT6 proteins were plotted and analyzed, an inverse correlation as shown in CRC cells was not observed in clinical samples from CRC patients (Supplementary Figure 2). 


\section{PRMT6 knockdown facilitates apoptosis of CRC cell lines}

To further investigate the effect of PRMT6 on apoptosis in CRC cells, we compared the ratio of apoptotic cells between siNC- and siPRMT6-transfected cells by flow cytometry. As shown in Figure 5A and Supplementary Figure 3, inhibition of PRMT6 expression resulted in significant induction of apoptosis in all CRC cells tested. To confirm these results, the expression levels of apoptosisrelated proteins were assessed, and we found that both the active form of caspase 3 and PARP degradation were clearly increased by PRMT6 depletion in three CRC cell lines (Figure 5B). Collectively, these results demonstrate that PRMT6 overexpression plays a critical role in suppressing apoptosis in CRC cells and that the enzyme can serve as an effective therapeutic target in CRC.

\section{DISCUSSION}

Fundamental biological processes regulated by protein arginine methylation include RNA processing, protein trafficking, signal transduction, and transcription [23]. Particularly, recent experimental evidence regarding genomic instability, DNA repair, and metastatic potential indicated oncogenic pathways involving arginine modification [8].

In the present study, we found that $23.7 \%$ of colorectal cancers showed positive staining of PRMT6 by immunohistochemistry and that the localization of the enzyme was exclusively nuclear. Among the clinical and pathological parameters listed in Table 1, PRMT6 expression was significantly associated with the degree of cancer cell differentiation. Although PRMT6 expression was not related to the OS of patients with CRC, Cox
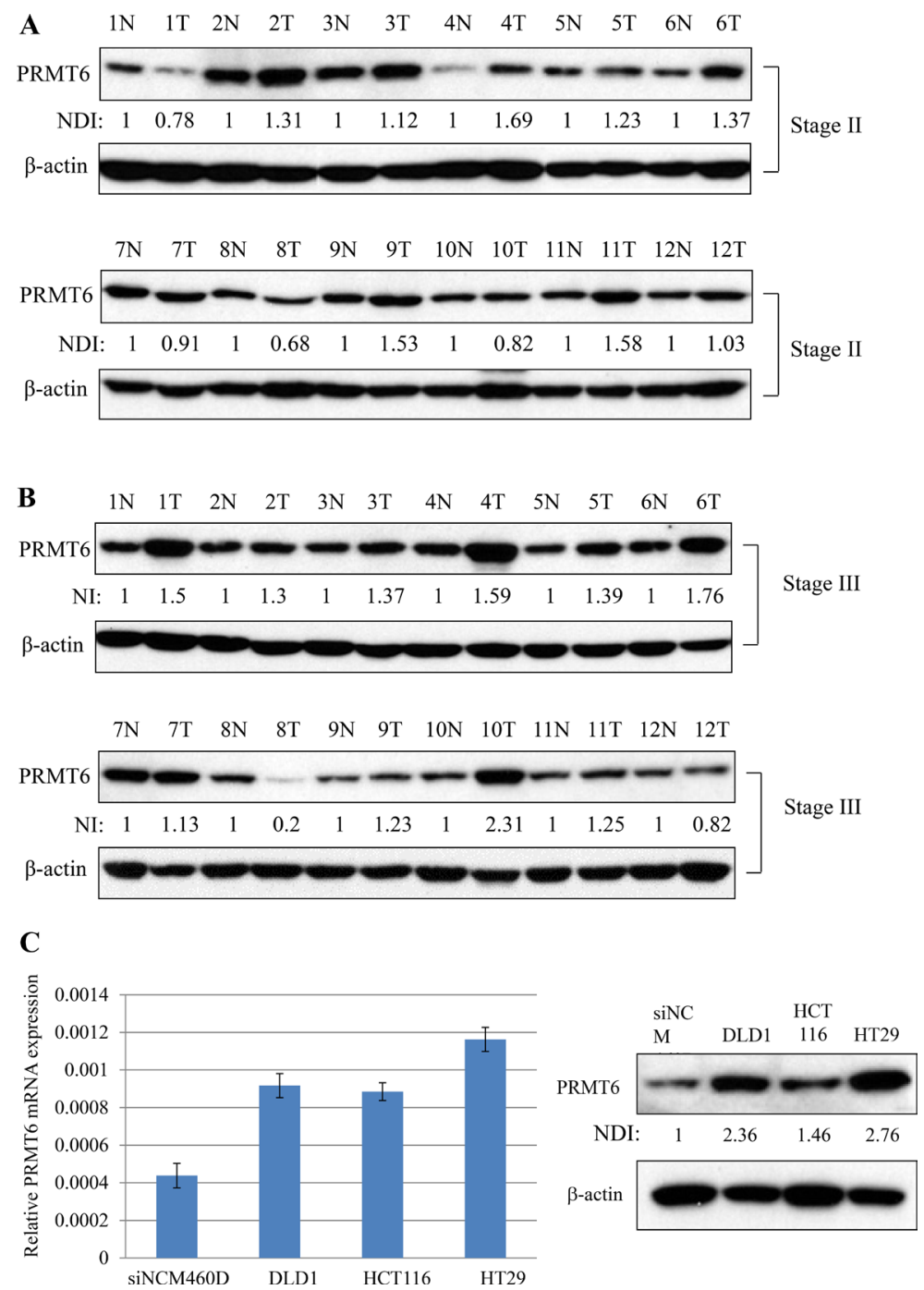

Figure 1: Overexpression of PRMT6 in CRC tissues and cell lines. (A) Comparison of PRMT6 expression between the primary $\mathrm{CRC}$ and adjacent normal tissues paired from the same patient with stage II. (B) The same experiments in panel (A) were carried out with tissue extracts from the patients with stage III. (C) PRMT6 mRNA and protein expression levels between NCM460D and three CRC cells were compared by real-time PCR (left panel) and western blotting (right panel), respectively. Densitometric intensity of PRMT6 protein was normalized to $\beta$-actin. NDI indicates normalized densitometric intensity. 
univariate and multivariate analyses revealed significant relationships between PRMT6 positivity and shorter DFS. These results were confirmed by Kaplan-Meier analysis. Previously, the expression of specific isoforms of PRMT1 variants were shown to be significantly associated with nodal status, TNM stage, and tumor grade [24, 25], and both PRMT4 and PRMT5 are highly expressed in colon cancer [26, 27]. However, among the PRMTs tested, only PRMT6 showed a significant association with disease-free survival, indicating that enzyme expression is a useful indicator of unfavorable prognosis for colon cancer.

Tumor suppressors such as p53, CDKN1B (p27), and p21 are often silenced or inactivated in human cancers, thereby allowing deregulation of CDK activity and cell cycle progression. In CRC, however, the expression of these genes as prognostic markers remains unclear [28, 29]. In addition, although $\mathrm{p} 21$ protein serves as a surrogate indicator for $\mathrm{p} 53$ protein alterations, there are discrepancies between p53 and p21 expression levels in CRC [30]. Collectively, these findings indicate the presence of $\mathrm{p} 53$ independent mechanisms of $\mathrm{p} 21$ regulation during CRC development. In the present study, we found that siRNAmediated PRMT6 depletion significantly induced p21 expression in all the three CRC cell lines (Figures 4A4C). Based on these results and those of previous studies [17-19], we examined the inverse correlation between hypomethylation of H3R2 by PRMT6 suppression and p21 induction in the three CRC cells. However, a correlation was only observed for HT29 cells (Figure 4A). For p53, while DLD1 and HT29 cells carrying mutated p53 (S241F and $\mathrm{R} 273 \mathrm{H}$, respectively [31]) showed no induction of p53 under PRMT6 suppression, HCT116 cells with wildtype p53 showed p53 upregulation (Figure 4A and 4B, respectively). Neault et al. [17]. reported that PRMT6 negatively regulates p53 gene expression by methylating H3R2 and consequently p21 expression is repressed in mouse embryonic fibroblasts. However, hypomethylation of H3R2 in PRMT6-suppressed HCT116 cells was not induced (Figure 4B). We analyzed the correlation between the two tumor suppressors and PRMT6 expression in clinical tissue samples as shown in Figure 1A; however, no inverse correlation shown in CRC cell lines was

\section{A}
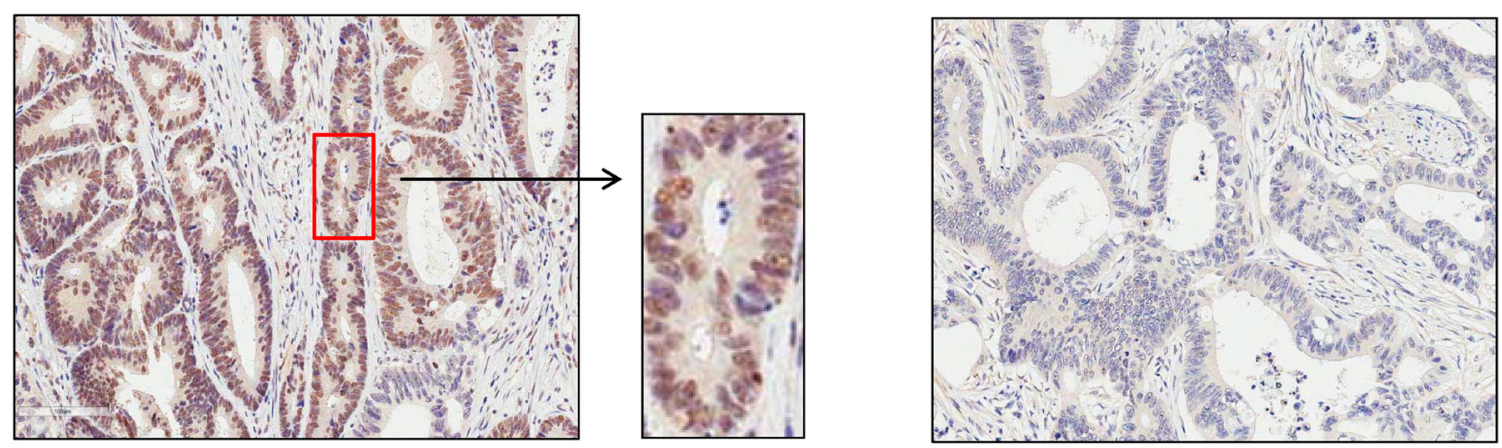

B
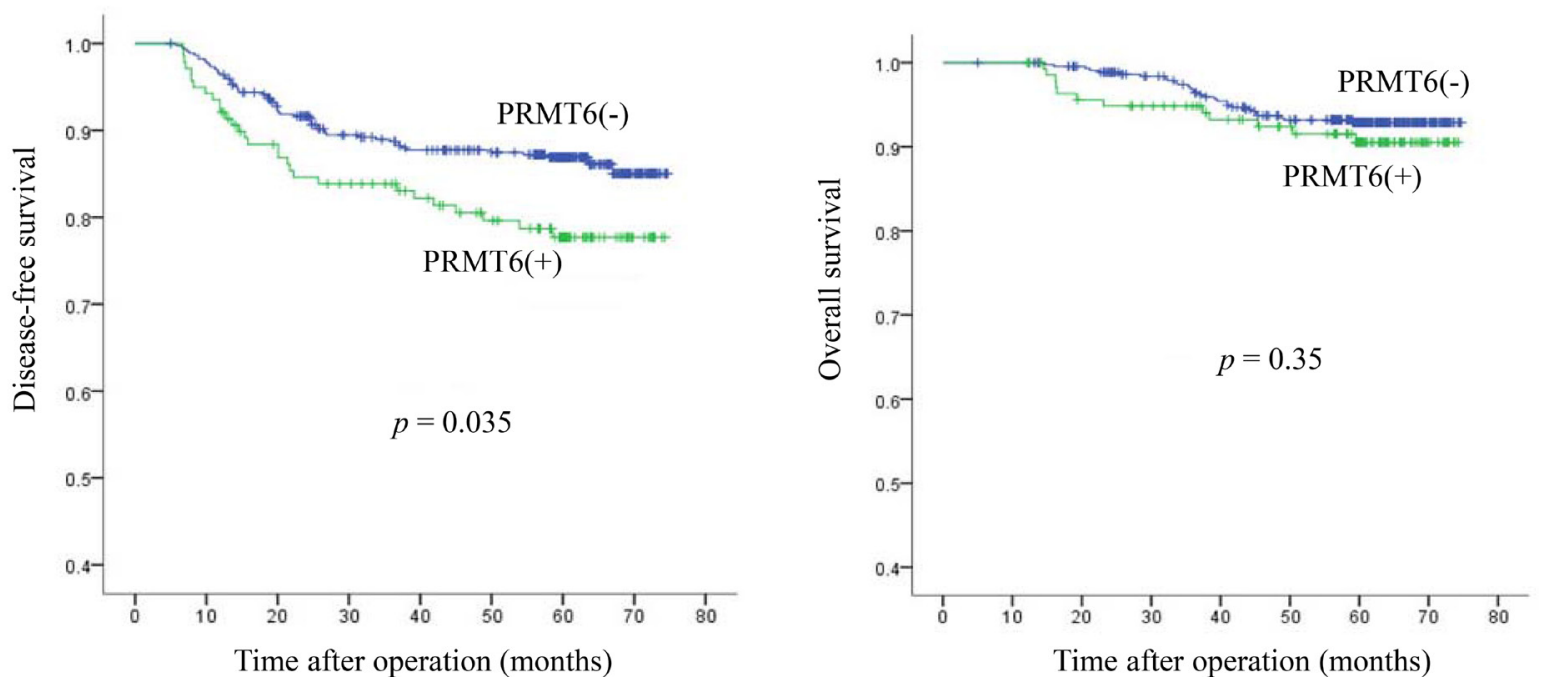

Figure 2: Clinical significance of PRMT6 overexpression in CRC tissues. (A) Representative images $(\times 100)$ of PRMT6 positive (left panel) and PRMT6-negative tumors (right panel) stained with anti-PRMT6 antibody from stage III CRC patients. (B) KaplanMeier survival curves according to the immunoexpression of PRMT6 protein. The left and right panels show disease-free and overall survival, respectively. 
observed in CRC tissues (Supplementary Figure 2). These findings suggest that $\mathrm{p} 21$ and $\mathrm{p} 53$ regulation by PRMT6 is cell type-specific rather than a general phenomenon in CRC.

Nakakido et al. [20] reported that arginine residue 156 in the p21 protein is methylated by PRMT6, enhancing cytosolic localization of the protein in HCT116 cells. We also detected p21 and PRMT6 in both the nuclear and cytosolic fractions, with much higher levels in the cytoplasm (Supplementary Figure 4A). Moreover, when PRMT6 expression was suppressed in HCT116 cells, the p21 ratio in the nucleus to cytoplasm increased compared to that of siNC (Supplementary Figure 4B). These results are consistent with those of Nakakido et al. In contrast, DLD1 and HT29 cells did not show an increased ratio of p21 in the nucleus to cytoplasm under PRMT6-KD (Supplementary Figure 4B), suggesting that the regulation of $\mathrm{p} 21$ localization by PRMT6 is not a general phenomenon in CRC cells.

PRMT6 suppression induced apoptosis in CRC cells and increased the expression of the cleavage forms of caspase 3 and PARP (Figure 5). As described above, PRMT6 depletion induces cell cycle arrest and senescence in several types of cancer cell lines [17,19,20]; however, PRMT6-mediated apoptosis in cancer cells has not been previously reported. Our results showed that PRMT6 is a promising target for pharmaceutical drug development, and the molecular mechanism underlying PRMT6-mediated CRC cell apoptosis should be further investigated.

\section{MATERIALS AND METHODS}

\section{Patient samples}

From June 2008 to May 2009, 1035 patients diagnosed with primary $\mathrm{CRC}$ underwent radical surgery at the Samsung Medical Center (Sungkyunkwan University School of Medicine) in Seoul, Korea. We obtained prior patient consent as well as approval from the Institutional Research Board to use clinical materials for research purposes. Among these
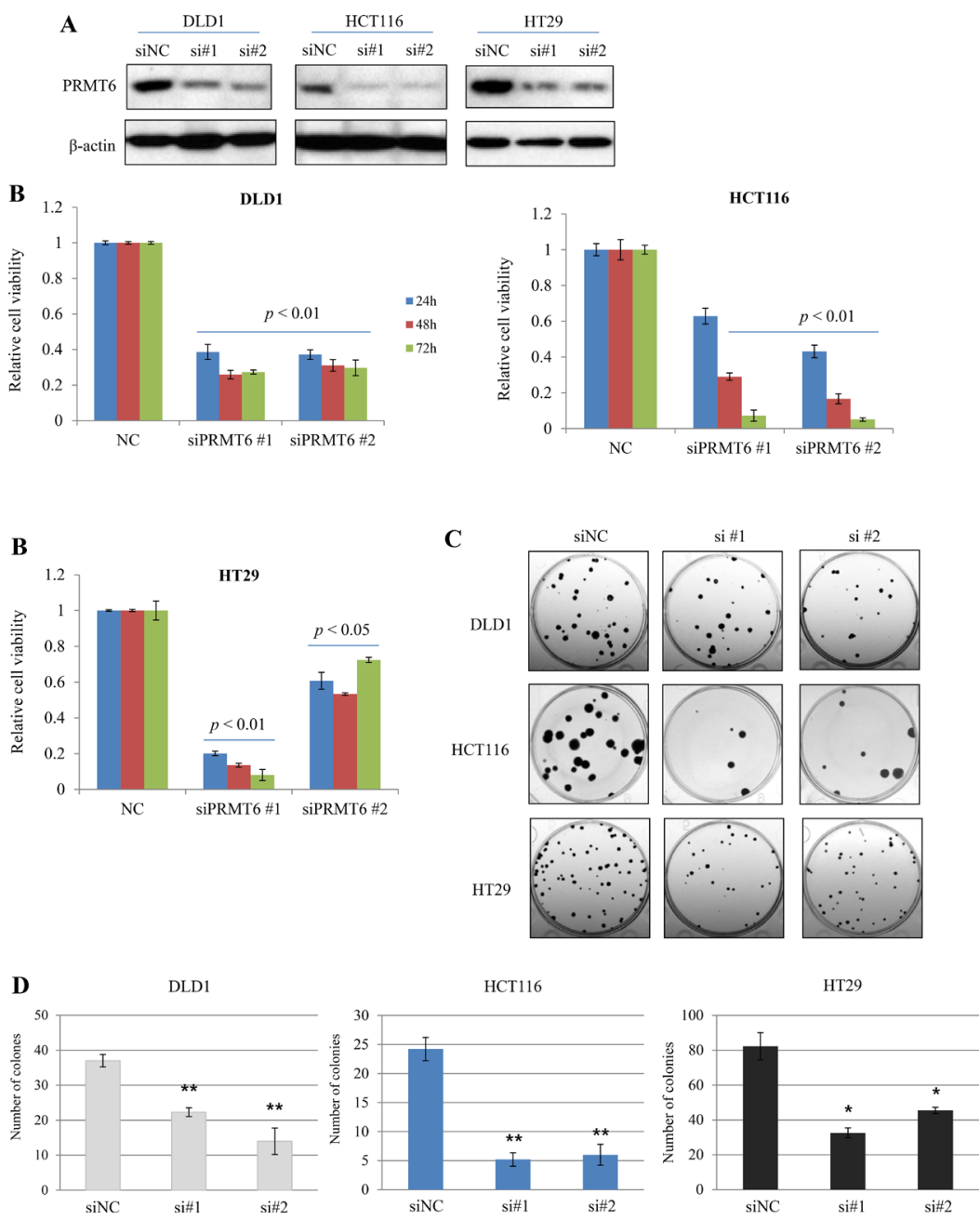

Figure 3: Inhibition of growth and colony-forming ability by downregulation of PRMT6 in CRC cell lines. (A) Knockdown of endogenous PRMT6 in three CRC cell lines by siRNAs transfection. (B) Suppression of PRMT6 inhibits cell growth as determined by a WST-1 based assay. (C) Representative stained plates of the CRC cells are shown and (D) the number of colonies was evaluated. Error bars denote SEM from three independent experiments. ${ }^{*}, p<0.05 ;{ }^{* *}, p<0.01$. 
patients, 621 were diagnosed with pathological stage II, IIIA, or IIIB CRC after surgery for the primary tumor. Following the exclusion of 26 patients with no tumors in specimens because they had already undergone previous polypectomy or endoscopic resection of the primary tumor before surgery and nine patients with damaged or unreadable slides, a total of 586 patients were included in the analysis. Comprehensive chart reviews were performed to obtain clinicopathological information, and follow-up data were obtained from the medical records and National Bureau of Statistics. The included variables were sex, age, tumor location (colon and rectum), preoperative carcinoembryonic antigen level (ng/ $\mathrm{mL}$ ), pathologic TNM stage, histopathological type (tumor differentiation status), lymphatic invasion, vascular invasion, perineural invasion, adjuvant chemotherapy, and expression of PRMT6 (negative/positive).
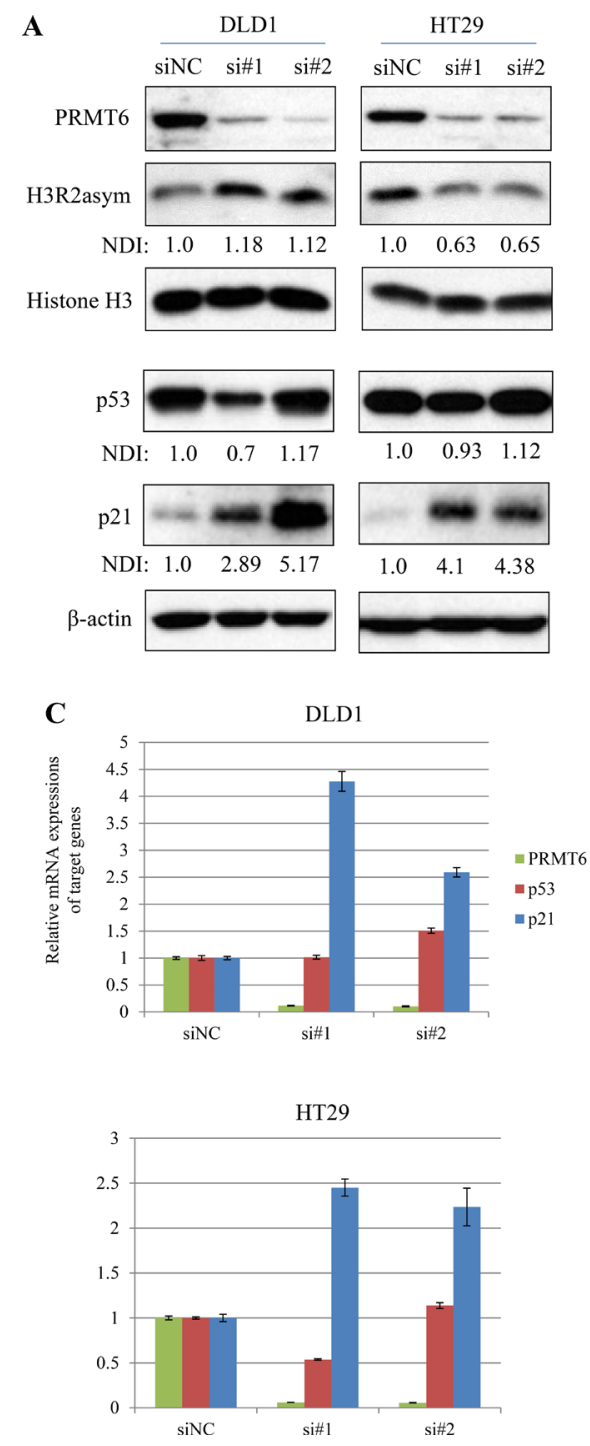

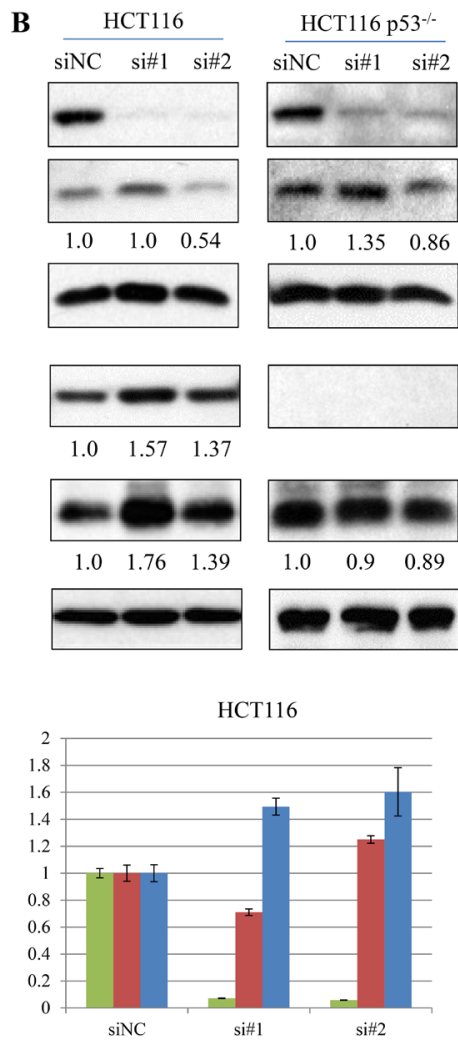

Adjuvant chemotherapy is typically recommended for patients diagnosed with stage III cancer or stage II cancer with high-risk factors. In our hospital, poor histopathological differentiation, positive lymphatic invasion, positive vascular invasion, and positive perineural invasion were regarded as highrisk factors in patients with stage II cancer. Adjuvant chemotherapy was performed from 2 to 3 weeks after discharge, and the most common treatment regimens were the following: (1) ftorafur plus uracil $(n=157)$; (2) capecitabine $\left(\mathrm{Xeloda}^{\circledR}\right)(n=129)$; (3) oxaliplatinbased chemotherapy $(n=85)$; and (4) intravenous 5 -fluorouracil-based chemotherapy $(n=12)$. Among patients with rectal cancers, 75 patients received preand post-operative radiotherapy.

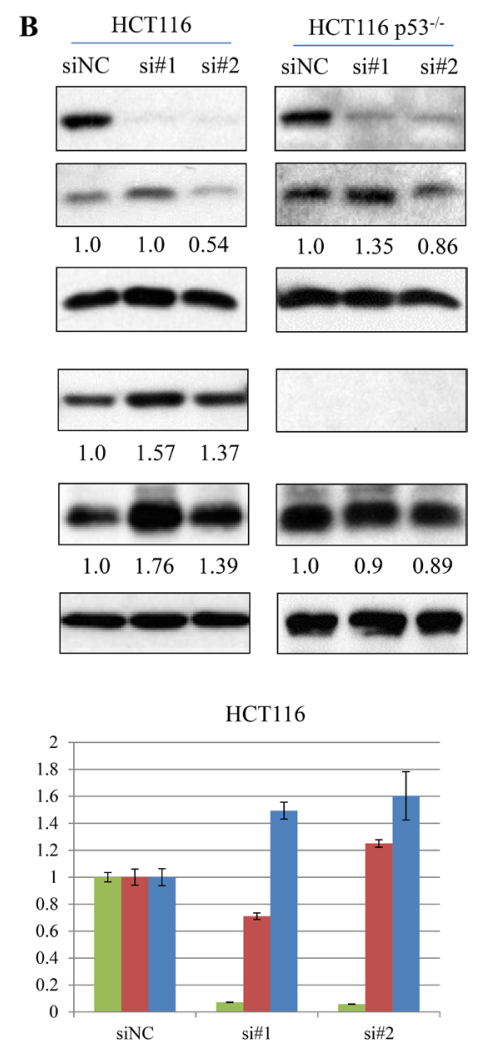




\section{Preparation of colon tissue extracts}

Twenty four frozen CRC tumors and matched adjacent normal tissues were collected after surgery and the tissue samples were immediately frozen in liquid nitrogen. For protein extraction, 50-100 mg of tissue was homogenized using a TissueLyser (Qiagen, Hilden, Germany) in lysis buffer (20 mM HEPES, $\mathrm{pH}$ 8.0, 9.0 $M$ urea, $1 \times$ protease and phosphatase inhibitors) and sonicated with three bursts of $30 \mathrm{~s}$ at $15 \mathrm{~W}$. The extracts were then centrifuged at $20,000 \times g$ at $4^{\circ} \mathrm{C}$ for $15 \mathrm{~min}$ and the supernatant was stored at $-80^{\circ} \mathrm{C}$ until use.

\section{Tissue microarray construction and immunohistochemical stains}

Tissue microarrays were constructed using the Quick Ray ${ }^{\circledR}$ Manual Tissue Microarrayer (Unitma Co., Ltd. Seoul, Korea). Specimens from four representative tumor regions were taken from donor formalin-fixed paraffinembedded blocks using a 2-mm core punch and arrayed into recipient blocks. Four 1- $\mu \mathrm{m}$-thick tissue microarray sections were labeled with rabbit polyclonal anti-PRMT6 antibody (Bethyl Laboratories, Inc., Montgomery, TX, USA). Tissue sections were deparaffinized three times in xylene for a total of $15 \mathrm{~min}$ and subsequently rehydrated. Immunostaining was performed using a BondMax autoimmunostainer with a Bond ${ }^{\mathrm{TM}}$ Polymer Refine Detection kit, DS9800 (Leica Biosystems, Wetzlar, Germany). Briefly, antigen retrieval was carried out at $97^{\circ} \mathrm{C}$ for 20 min in Bond ${ }^{\mathrm{TM}}$ Epitope Retrieval Solution
1. After blocking endogenous peroxidase activity with $3 \%$ hydrogen peroxidase for $10 \mathrm{~min}$, primary antibody incubation was carried out for $15 \mathrm{~min}$ at room temperature at a dilution of 1:200. Counter-staining was performed with Mayer's hematoxylin. Negative controls (substitution of TBS for primary antibody) were run simultaneously. Staining for PRMT6 was considered positive when tumor cells showed nuclear reactivity in more than two of four cores (Figure 2A).

\section{Cell culture}

The human normal epithelial cell line (NCM460D) derived from the colon mucosa was purchased from INCELL Corporation (San Antonio, TX, USA). NCM460D cells were cultured in MA3 medium. Three human colon cancer cell lines, DLD-1, HCT116, and HT29, were obtained from the American Type Culture Collection (Manassas, VA, USA). DLD1 and HT29 cells were cultured in RPMI-1640. HCT116 cells and p53-null HCT116 cells were maintained in McCoy's 5A medium. All culture media were supplemented with $10 \%$ fetal bovine serum and $1 \%$ penicillin/streptomycin (GIBCO, Grand Island, NY, USA). Cells were maintained at $37^{\circ} \mathrm{C}$ with $5 \% \mathrm{CO}_{2}$.

\section{SiRNA transfection}

SiRNA oligonucleotide duplexes were purchased from Integrated DNA Technologies (Coralville, IA, USA). The siRNA sequences
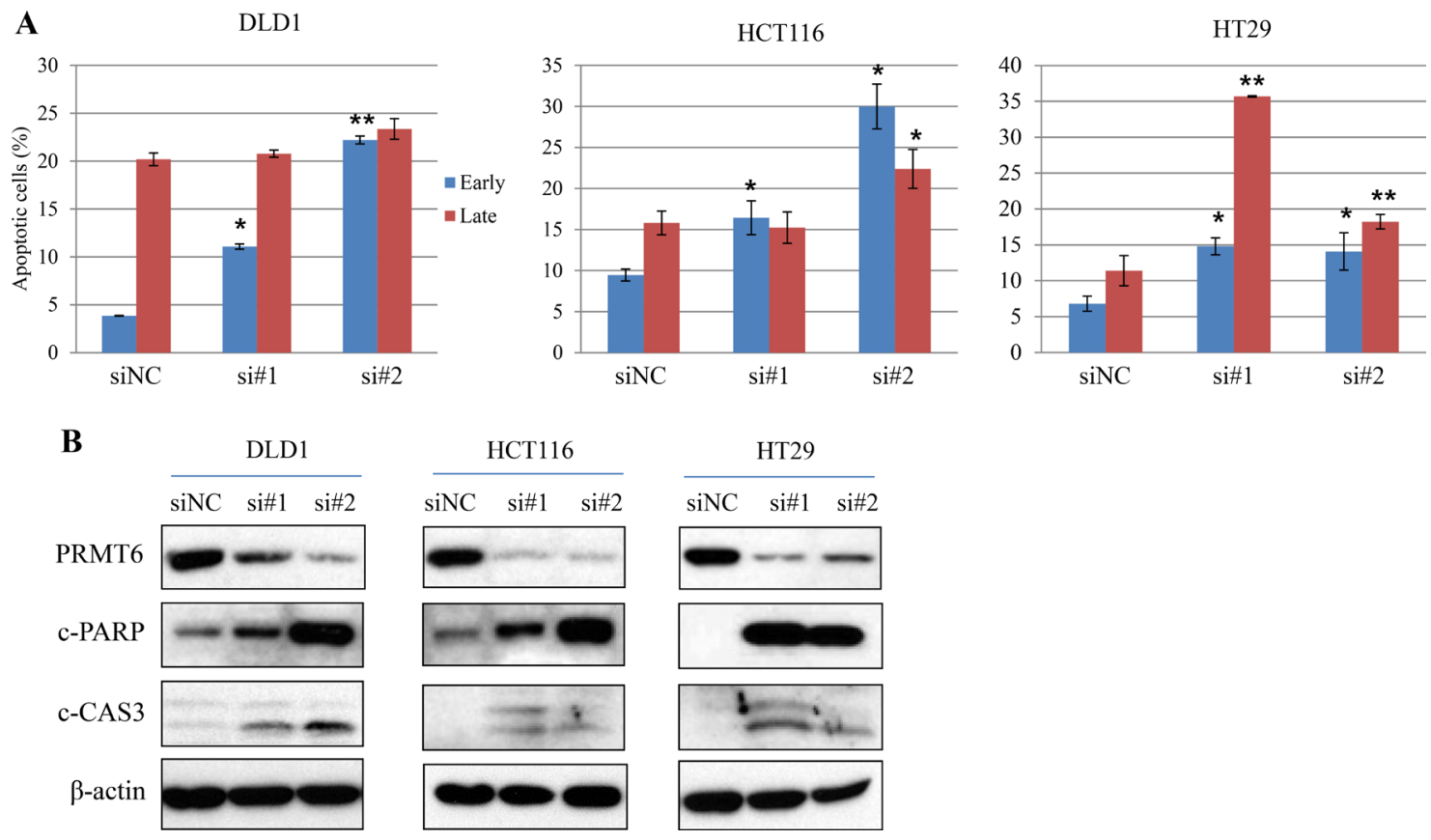

Figure 5: Induction of apoptosis of three CRC cells by PRMT6 knockdown. (A) Quantification of the mean annexin-V and propidium iodide fluorescence in early and late apoptotic cell populations with three independent experiments. Representative scatter plots of each cell lines are presented in Supplementary Figure 3. ${ }^{*}, p<0.05 ;^{* *}, p<0.01$. (B) Induction of cleaved forms of caspase 3 and PARP proteins in PRMT6-suppressed CRC cells. 
were as follows: PRMT6 siRNA \#1 (sense, ACAGCAUACCUAAGAAACUCAGAA G; antisense, CUUCUGAGUUUCUUAGGUAUGCUGUAC), PRMT6 SIRNA \#2 (sense, CUACUUACAAGUAGUGAAAGUUCCC; antisense, GGGAACUUUCACUACUUGUAAGUA GGC). Cells in six-well culture plates were transfected with increasing concentrations of siRNAs (see Figure 1) using Lipofectamine RNAiMAX (Life Technologies, Carlsbad, CA, USA) according to the manufacturer's instructions.

\section{Cell proliferation assay}

The metabolic activity of cells was assessed by indirectly measuring cell viability using CellVia (AbFrontier, Seoul, Korea) according to the manufacturer's instructions. CRC cells were transfected with PRMT6 siRNAs as described above and seeded in 96-well plates at a density of $5 \times 10^{3}$ cells in $100 \mu \mathrm{L}$ medium per well. After transfection, at each point, $10 \mu \mathrm{L}$ of the reagent was added to each well and the plates were incubated at $37^{\circ} \mathrm{C}$ for $3 \mathrm{~h}$ Reduction of the water-soluble tetrazolium salt WST-1 to formazan was determined using an enzyme-linked immunosorbent assay reader at $450 \mathrm{~nm}$.

\section{Colony formation assay (CFA)}

We seeded 100 viable cells per well into six-well plates $24 \mathrm{~h}$ post-transfection. The cells were cultured for 10-14 days with media changes every 2-3 days. To visualize the colonies, the medium was removed and the cells were washed with PBS and stained with a staining solution containing $0.5 \%$ crystal violet and $6 \%$ glutaraldehyde for $30 \mathrm{~min}$ at room temperature [32]. The colonies were scored under a microscope and data are presented as the mean number of colonies \pm standard deviation (SD) from three independent experiments.

\section{Apoptosis assay}

Apoptosis was quantitated by flow cytometry using an annexin V-fluorescein isothiocyanate (FITC)/propidium iodide (PI) kit according to the manufacturer's instructions (BD Bioscience, Franklin Lakes, NJ, USA). After $48 \mathrm{~h}$ post-transfection with siNC and siPRMT6s, Cells were washed with PBS and suspended in annexin $\mathrm{V}$ binding buffer, and annexin V-FITC solution and PI were added. Next, the cells were incubated at room temperature for $15 \mathrm{~min}$. The stained cells were analyzed by fluorescenceactivated cell sorting (BD FACSAria ${ }^{\mathrm{TM}}$; BD Biosciences). The data were analyzed using FACSDiva ${ }^{\mathrm{TM}}$ software (BD Biosciences).

\section{Western blot analysis}

Equal amounts of colon tissue or cancer cell extracts were subjected to sodium dodecyl sulfate polyacrylamide gel electrophoresis and transferred onto polyvinylidene fluoride membranes (Millipore, Billerica, MA, USA). The membranes were incubated overnight at $4{ }^{\circ} \mathrm{C}$ with antibodies against PRMT6 (1:1000 dilution, Cell Signaling Technology, Danvers, MA, USA), cleaved PARP (1:1000; Cell Signaling Technology), $\beta$-actin (1:10,000; Santa Cruz Biotechnology, Santa Cruz, CA, USA), mono- and dimethyl arginine (1:500; Abcam, Cambridge, UK), p21 (1:1000, Cell Signaling Technology), p53(1:5000, Santa Cruz), histone H3 (1:50000, Abcam), H3R2me2a (1:500, Novus Biologicals, Littleton, CO, USA). Subsequently, the membranes were incubated with the secondary antibodies for $1 \mathrm{~h}$ at room temperature, and an Immobilon Western Chemiluminescent HRP Substrate (Millipore) was used for detection. The relative protein levels were calculated by comparison to the levels of $\beta$-actin.

\section{Quantitative real time PRC}

RNA was extracted from cell lines using TRIzol® (Invitrogen, Carlsbad, CA, USA). High-capacity cDNA Reverse Transcription Kit from Applied Biosystems (Foster City, CA, USA) enabled first strand synthesis. PCR reactions were carried out using LightCycler 96 System (Roche Diagnostic) following the manufacture's protocol. Primer sequences for human GAPDH (housekeeping gene), PRMT6, p21 and p53 are presented in Supplementary Table 1.

\section{Statistical analysis}

Statistical analysis was performed using SPSS version 18.0 software (SPSS Inc., Chicago, IL, USA). In all patients, DFS was defined as the interval between the date of surgery and date of the first detection of recurrence or date of the last known follow-up without evidence of recurrence. OS was the time of the last visit for regular follow-up. Statistical analyses comparing the two groups were performed using $t$-tests, $\chi^{2}$ tests, or Fisher's exact tests. Regression analysis was performed using the Cox proportional hazard regression model for both univariate and multivariate analyses. Survival rates were estimated using the Kaplan-Meier method and compared with the log-rank test. Statistical results were considered significant if $p<0.05$.

\section{Abbreviations}

PRMT, protein arginine methyltransferase; CRC, colorectal cancer; OS, overall survival; DFS, diseasefree survival; FITC, fluorescein isothiocyanate; PI, propidium iodide. 


\section{Author contributions}

Y.L. designed the experiments and wrote the manuscript. S.Y.Y., L.C., and Y.H.K. performed in vitro studies and data analysis. J-A.Y. acquired human tissue samples and performed statistical analyses. I.G.D. carried out and analyzed IHC with human tissue samples (positive or negative staining). H.C.K. obtained funding and supervised the research.

\section{ACKNOWLEDGMENTS}

We thank Dr. Choi Jane at University of Ulsan for providing the HCT116 p53-/- cell line.

\section{CONFLICTS OF INTEREST}

The authors declare no conflicts of interest.

\section{FUNDING}

This work was supported by the National Research Foundation of Korea (NRF) grant funded by the Korea government (MSIP) (No. 2014R1A2A2A01004362) and Basic Science Research Program through the NRF funded by the Ministry of Education (2016R1A6A3A11931284).

\section{REFERENCES}

1. Jemal A, Bray F, Center MM, Ferlay J, Ward E, Forman D. Global cancer statistics. CA Cancer J Clin. 2011; 61:69-90.

2. Winawer SJ, Zauber AG. The advanced adenoma as the primary target of screening. Gastrointest Endosc Clin N Am. 2002; 12:1-9, v.

3. Rupnarain C, Dlamini Z, Naicker S, Bhoola K. Colon cancer: genomics and apoptotic events. Biol Chem. 2004; 385:449-464.

4. Calvert PM, Frucht $\mathrm{H}$. The genetics of colorectal cancer. Ann Intern Med. 2002; 137:603-612.

5. Weisenberger DJ, Siegmund KD, Campan M, Young J, Long TI, Faasse MA, Kang GH, Widschwendter M, Weener D, Buchanan D, Koh H, Simms L, Barker M, et al. $\mathrm{CpG}$ island methylator phenotype underlies sporadic microsatellite instability and is tightly associated with BRAF mutation in colorectal cancer. Nat Genet. 2006; 38:787-793.

6. Paik WK, Paik DC, Kim S. Historical review: the field of protein methylation. Trends Biochem Sci. 2007; 32:146-152.

7. Bedford MT, Richard S. Arginine methylation an emerging regulator of protein function. Mol Cell. 2005; 18:263-272.

8. Yang Y, Bedford MT. Protein arginine methyltransferases and cancer. Nat Rev Cancer. 2013; 13:37-50.

9. Li T, Kong AN, Ma Z, Liu H, Liu P, Xiao Y, Jiang X, Wang L. Protein arginine methyltransferase 1 may be involved in pregnane $\mathrm{x}$ receptor-activated overexpression of multidrug resistance 1 gene during acquired multidrug resistant. Oncotarget. 2016; 7:20236-20248. https://doi. org/10.18632/oncotarget.7752.

10. Poulard C, Corbo L, Le Romancer M. Protein arginine methylation/demethylation and cancer. Oncotarget. 2016; 7:67532-67550. https://doi.org/10.18632/oncotarget.11376.

11. Cha B, Jho EH. Protein arginine methyltransferases (PRMTs) as therapeutic targets. Expert Opin Ther Targets. 2012; 16:651-664.

12. Frankel A, Yadav N, Lee J, Branscombe TL, Clarke S, Bedford MT. The novel human protein arginine N-methyltransferase PRMT6 is a nuclear enzyme displaying unique substrate specificity. J Biol Chem. 2002; 277:3537-3543.

13. El-Andaloussi N, Valovka T, Toueille M, Steinacher R, Focke F, Gehrig P, Covic M, Hassa PO, Schar P, Hubscher $\mathrm{U}$, Hottiger MO. Arginine methylation regulates DNA polymerase beta. Mol Cell. 2006; 22:51-62.

14. Hyllus D, Stein C, Schnabel K, Schiltz E, Imhof A, Dou Y, Hsieh J, Bauer UM. PRMT6-mediated methylation of R2 in histone H3 antagonizes H3 K4 trimethylation. Genes Dev. 2007; 21:3369-3380.

15. Lim Y, Lee E, Lee J, Oh S, Kim S. Down-regulation of asymmetric arginine methylation during replicative and $\mathrm{H} 2 \mathrm{O} 2$-induced premature senescence in WI-38 human diploid fibroblasts. J Biochem. 2008; 144:523-529.

16. Kim C, Lim Y, Yoo BC, Won NH, Kim S, Kim G. Regulation of post-translational protein arginine methylation during HeLa cell cycle. Biochim Biophys Acta. 2010; 1800:977-985.

17. Neault M, Mallette FA, Vogel G, Michaud-Levesque J, Richard S. Ablation of PRMT6 reveals a role as a negative transcriptional regulator of the p53 tumor suppressor. Nucleic Acids Res. 2012; 40:9513-9521.

18. Phalke S, Mzoughi S, Bezzi M, Jennifer N, Mok WC, Low DH, Thike AA, Kuznetsov VA, Tan PH, Voorhoeve PM, Guccione E. p53-Independent regulation of p21Waf1/Cip1 expression and senescence by PRMT6. Nucleic Acids Res. 2012; 40:9534-9542.

19. Stein C, Riedl S, Ruthnick D, Notzold RR, Bauer UM. The arginine methyltransferase PRMT6 regulates cell proliferation and senescence through transcriptional repression of tumor suppressor genes. Nucleic Acids Res. 2012; 40:9522-9533.

20. Nakakido M, Deng Z, Suzuki T, Dohmae N, Nkamura Y, Hamamoto R. PRMT6 increase cytoplasmic localization of p21CDKN1A in cancer cells through arginine methylation and makes more resistant to cytotoxic agents. Oncotarget. 2015; 6:30957-30967. https://doi.org/10.18632/oncotarget.5143.

21. Yoshimatsu M, Toyokawa G, Hayami S, Unoki M, Tsunoda T, Field HI, Kelly JD, Neal DE, Maehara Y, Ponder BA, Nakamura Y, Hamamoto R. Dysregulation of PRMT1 and PRMT6, Type I arginine methyltransferases, is involved in various types of human cancers. Int J Cancer. 2011; 128:562-573. 
22. Almeida-Rios D, Graça I, Vieira FQ, Ramalho-Carvalho J, Pereira-Silva E, Martins AT, Oliveira J, Gonçalves CS, Costa BM, Henrique R, Jerónimo C. Histone methyltransferase PRMT6 plays an oncogenic role of in prostate cancer. Oncotarget. 2016; 7:53018-53028. https:// doi.org/10.18632/oncotarget.10061.

23. Bedford MT, Clarke SG. Protein arginine methylation in mammals: who, what, and why. Mol Cell. 2009; 33:1-13.

24. Mathioudaki K, Papadokostopoulou A, Scorilas A, Xynopoulos D, Agnanti N, Talieri M. The PRMT1 gene expression pattern in colon cancer. Br J Cancer. 2008; 99:2094-2099.

25. Papadokostopoulou A, Mathioudaki K, Scorilas A, Xynopoulos D, Ardavanis A, Kouroumalis E, Talieri M. Colon Cancer and Protein Arginine Methyltransferase 1 Gene Expression. Anticancer Res. 2009; 29:1361-1366.

26. Kim YR, Lee BK, Park RY. Differential CARM1 expression in prostate and colorectal cancers. BMC cancer. 2010; 10:197.

27. Cho EC, Zheng S, Munro S. Arginine methylation controls growth regulation by E2F-1. The EMBO journal. 2012; 31:1785-97.
28. Soong R, Powell B, Elsaleh H, Gnanasampanthan G, Smith DR, Goh HS, Joseph D, Iacopetta B. Prognostic significance of TP53 gene mutation in 995 cases of colorectal carcinoma. Influence of tumour site, stage, adjuvant chemotherapy and type of mutation. Eur J Cancer. 2000; 36:2053-2060.

29. Lebe B, Sarioglu S, Sokmen S, Ellidokuz H, Fuzun M, Kupelioglu A. The clinical significance of p53, p21, and p27 expressions in rectal carcinoma. Appl Immunohistochem Mol Morphol. 2005; 13:38-44.

30. Noske A, Lipka S, Budczies J, Muller K, Loddenkemper C, Buhr HJ, Kruschewski M. Combination of p53 expression and p21 loss has an independent prognostic impact on sporadic colorectal cancer. Oncol Rep. 2009; 22:3-9.

31. Rodrugues NR, Rowan A, Smith ME, Kerr IB, Bodmer WF, Gannon JV, Lane DP. p53 mutations in colorectal cancer. Proc Natl Acad Sci USA. 1990; 87:7555-7559.

32. Franken NA, Rodermond HM, Stap J, Haveman J, van Bree C. Clonogenic assay of cells in vitro. Nat Protoc. 2006; 1:2315-2319. 